\title{
Quality management in South African architectural practices
}

\section{Paul Munting and Hoffie Cruywagen ${ }^{\mathrm{b}}$}

\author{
${ }^{a}$ University of Pretoria, South Africa \\ ${ }^{\mathrm{b}}$ Department of Construction Economics, University of Pretoria, South Africa
}

\begin{abstract}
The building and construction industries worldwide are experiencing ever closer scrutiny of their operations as pressure mounts from clients to address the inefficiencies inherent therein. The issue of quality is of pivotal concern in this regard and this paper examines the status quo of a number of South African architectural practices with respect to how they are managing quality, and tests their opinions with regard to ISO 9000 certification as a means of addressing the issue. The results indicate that the architects in question generally have a poor grasp of quality management theory, although many of the eight main principles required for its implementation are already intrinsically present in the way they manage their practices; probably as a result of the small size of the average practice. A systematic and documented approach to quality management is however largely lacking in the profession and a great deal of negativity exists with regard to ISO 9000 certification.
\end{abstract}

\section{Article Outline}

1. Introduction

2. Research methodology

3. Quality management and professionals

4. Architects and quality management

5. Survey structure and distribution 


\author{
6. Findings \\ 6.1. Section 1: respondent profile \\ 6.2. Section 2: management principles \\ 6.3. Section 3: quality management systems and procedures \\ 6.4. Section 4: perceptions \\ 7. Conclusions and recommendations \\ References
}

\title{
1. Introduction
}

South Africa, notwithstanding its geographically remote location, does not exist in isolation from the global economy. As such the contemporary trend toward globalisation, together with the advent of the Internet and recent advances in information technology and desktop processing expose local business to the full brunt of international competition and the complexities of the global market place. In this highly competitive climate the pressure is constantly mounting for local business to meet international standards in order just to maintain their market position. Since the recession of 1998 it has also become a common survival strategy among South African contractors, as well as building industry professionals, to expand their operations into the international arena, thereby mitigating the effects of the local economic cycle on business turnover.

This trend is likely to continue into the foreseeable future, and will have an everincreasing reach into ever-smaller local businesses. While the urgency and pertinence of quality to the architectural profession has been receiving attention in the UK since the mid eighties [1], in so far as the building industry professions in South Africa are concerned it appears that the architectural profession is slow at realising the benefits of quality management, and will in all probability take yet some time to embrace the discipline wholeheartedly. At present the South African association of consulting engineers (SAACE) [2] have implemented an incremental plan as of January 2006 whereby all of their members are required to initiate the development and application of a quality management system to their business processes over the subsequent 3 years. As yet there is little talk of other professional bodies following suit but it is envisaged that 
the requirements of influential clients/client bodies and the constant pressure of competition are likely to enforce the trend in the near future. This should not be seen in a negative light, as the benefits of applying quality management (QM) can be highly advantageous to such firms and their professional staff [3]. It is therefore in all probability only a matter of time before the other professions are compelled to follow suit.

Worldwide the building and construction industries are increasingly in the spotlight, as clients demand that the procurement processes in these sectors be closely re-examined. This is in a large part due to the fact that these industries have been slow to modernise and incorporate the benefits of recent technological advances, and are still highly wasteful and inefficient. This was highlighted in the UK by the Latham [4] and DTLR [5] reports, commissioned by the Prime Minister, and which resulted in the publication of the three best practice standards that now define the culture, relationships and processes of UK construction procurement. Internationally, the 1995 report by the Construction and Building sub committee of the Committee on Civil Industrial Technology (CCIT), part of the National Science and Technology Council of the United States, sets a similar standard. All these documents aim to radically reform the building industry and improve performance by $30-50 \%$, and are set to fundamentally alter the face of these industries within the next decade. All of the issues are quality related, and professionals in the industry can expect to experience increasing pressure to conform to international quality standards in the wake of the reforms that these reports aim to bring about.

A study by Rwelamila, [6] indicates that quality related problems also prevail in the local industry, and that at the end of the day "site managers, along with their supervisors, establish quality and their decisions are highly arbitrary”. This is despite the existence of specifications that extensively reference British and/or South African Standards and codes of practice.

The architectural profession often lags behind other building industry professions in the realm of enterprise management, possibly as a result of the strong task orientation and 
design focus of top management [7]. The fact that most architectural practices are small consultancies with one or two principles may also contribute to the tendency, as time spent on management is always at the expense of production. The extent to which quality management is applied in the practice locally is unknown, and few detailed guidelines exist for the implementation thereof to professional architectural service providers. It is in this context that this study was carried out, with the intention of shedding some light on the status quo and the way forward.

\section{Research methodology}

The aim of the study was to obtain an understanding of the manner in which quality is presently being managed within the South African architectural profession, to establish the extent to which current quality management theory and standards are being applied to such management practices, and to test the opinions of Architects in relation to ISO 9000 registration. The nature of the problem required that both a descriptive qualitative and a descriptive quantitative approach to the body of research be adopted.

In order to establish the quantitative criteria whereby architects could be evaluated a literature study was conducted from which the descriptive parameters relating to quality management in the architectural profession were composed. Due to the sample size and its distribution it was not feasible to adopt a qualitative approach that utilised personal interviews, and a questionnaire was circulated via email to architects registered with the South African Council for the Architectural Profession (SACAP) in order to capture the requisite data. This data was then analysed to provide a description of the status quo of QM among the respondents.

\section{Quality management and professionals}

When viewed against the abundance of literature relating to QM and total quality management (TQM) in the production and service industries, a relative paucity of publications relating the discipline to professionals and professional service firms is apparent. This is confirmed by Haywood-Farmer and Nollet [3] as well as McAdam and 
Canning [8], and as such professional service providers can be considered relative latecomers to the discipline of formally applied quality management systems. However, the subsequent decade has seen a trend among developed nations, especially in Europe, whereby professionals are under increasing pressure from powerful client bodies such as government, to subject themselves to disciplined and structured quality management devices.

In places, particularly the UK, this and other factors have often resulted in an inordinate emphasis on certification and quality assurance, rather than total quality management and customer satisfaction [9]. This is confirmed by McAdam and Canning's [8] finding that the reasons cited for ISO 9000 registration and the implementation of a quality management system among professionals surveyed in Ireland are not a drive toward improved quality as a competitive business strategy, as the literature would suggest it should be. Rather, these organisations were motivated primarily by the perception that certification would improve their market image and the firm's chances of procuring work from public sector clients. Overall, the results of the study indicated a disturbing lack of association between business improvement and ISO 9000 among these professional firms, thus calling into question one of the central tenets of ISO 9000. This is an important finding and should be borne in mind when considering a course of action for South African professionals, as it would appear that if the drive toward the implementation of a quality management system (QMS) and certification is not motivated by a real determination and commitment to improve quality and satisfy customers the results can be disappointing.

Professional service firms are possessed of a number of characteristics that profoundly influence the manner in which quality is managed by them, and which differs from large scale production industry where much of the QM theory has its origin. Van der Bij and Broekhuis [10] classify organisations as either bureaucratic or professional and list high input uncertainty and the difficulty of controlling and coordinating work processes by the standardisation of work methods as the two most important characteristics of the professional organisation. They argue that professional firms rather control and 
coordinate work processes by the standardisation of knowledge, which makes auditing difficult and conclude that it is not wise therefore to use ISO 9000 to audit a professional quality system. While this finding may be largely true for medical, legal and other professionals, it is somewhat less so for building industry professionals where typical project work processes/plans of work can be used as a foundation for such standardisation and input uncertainty can be progressively reduced by meticulous brief development. The above authors in fact allude to this by mentioning that the boundaries of their classification are not clearly stratified and that design offices (for example) usually have the characteristics suitable to both bureaucratic and professional quality systems.

Another inherent characteristic of professional service firms is their size; most are small to medium-sized organisations with a definite bias toward small. This presents some serious challenges as the resources required to develop, implement and maintain a certified QMS system can be prohibitive, and it is argued with some justification that the management concepts appropriate for the needs of large organisations may prove ineffective in small and medium-sized enterprises (SMEs), and indeed may even produce adverse results [11]. What is encouraging however, is that in terms of QM, and particularly TQM there are many advantages to being a small organisation as it is easier to effect the cultural change that inevitably accompanies the implementation thereof. Also the inherent characteristics of SMEs in some key areas such as market focus, proximity of individuals and corporate goals, the extent of the functional integration, employee awareness and team spirit, are likely to be closer to the requirements of the QM environment. Recognising the importance of individuals, trust, and empowerment of staff were among other issues where SMEs were thought to be close to the requirements of QM. In these respects therefore SMEs often possess the basic TQM core by virtue of their inherent characteristics, but need to build on this existing foundation.

In terms of the suitability of TQM to professional service firms [3] conclude that despite the professional need for autonomy in diagnosing and prescribing solutions, which at first glance appears to be in conflict with the discipline of the TQM philosophy, TQM can and 
does work in professional firms but has to be judiciously and assertively implemented with the involvement of the entire workforce. What is true for TQM in this regard is also true in a lesser degree for conventional QM solutions but it is of paramount importance however that the design of the QMS for such a firm is developed with the inherent characteristics of the organisation in mind [10].

\section{Architects and quality management}

The essential service that architects provide within the building project context is that of design. The importance thereof is well illustrated by the attention that the ISO 9000 standard lavishes on design [12] and the fact so much of the downstream quality is dependent on it. By way of example, 2 independent studies conducted in the UK concluded that $33-50 \%$ of failures in the building industry were attributable to design and another $40-41 \%$ to construction faults [13]. When compared to the $10-25 \%$ of product faults it is not surprising that UK government elected shortly thereafter to force quality management onto design consultants and construction contractors as a means to addressing the problem.

Fynes and De Burca [14], in their article on the effects of design quality on quality performance found that design quality is a major cost driver of the final product, and that it has substantial direct and indirect effects on other measures of performance such as conformance quality, quality-in-use, time-to-market and, to a lesser extent, customer satisfaction. They conclude that from a management perspective there is a need to recognise the pivotal role design quality plays in the overall spectrum of quality performance and that designing quality into a product will reduce costs, improve quality in the market place and improve temporal competitiveness. This is confirmed by Ahire and Dreyfus [15] who conclude that to attain superior quality outcomes, firms need to balance their design and process management efforts, and persevere with the long term implementation of both.

The important role that architects play as designers and the effect they have on quality within the construction project lifecycle is illustrated by Arditi and Gunaydin [16] (Fig. 
1) in the context of the expanded TQM definition of the customer as any beneficiary of an upstream process. Thus the architect/engineer becomes a customer of the client (as the recipient of the brief) and the constructor becomes the client of the architect/engineer (as the recipient of the design) etc.

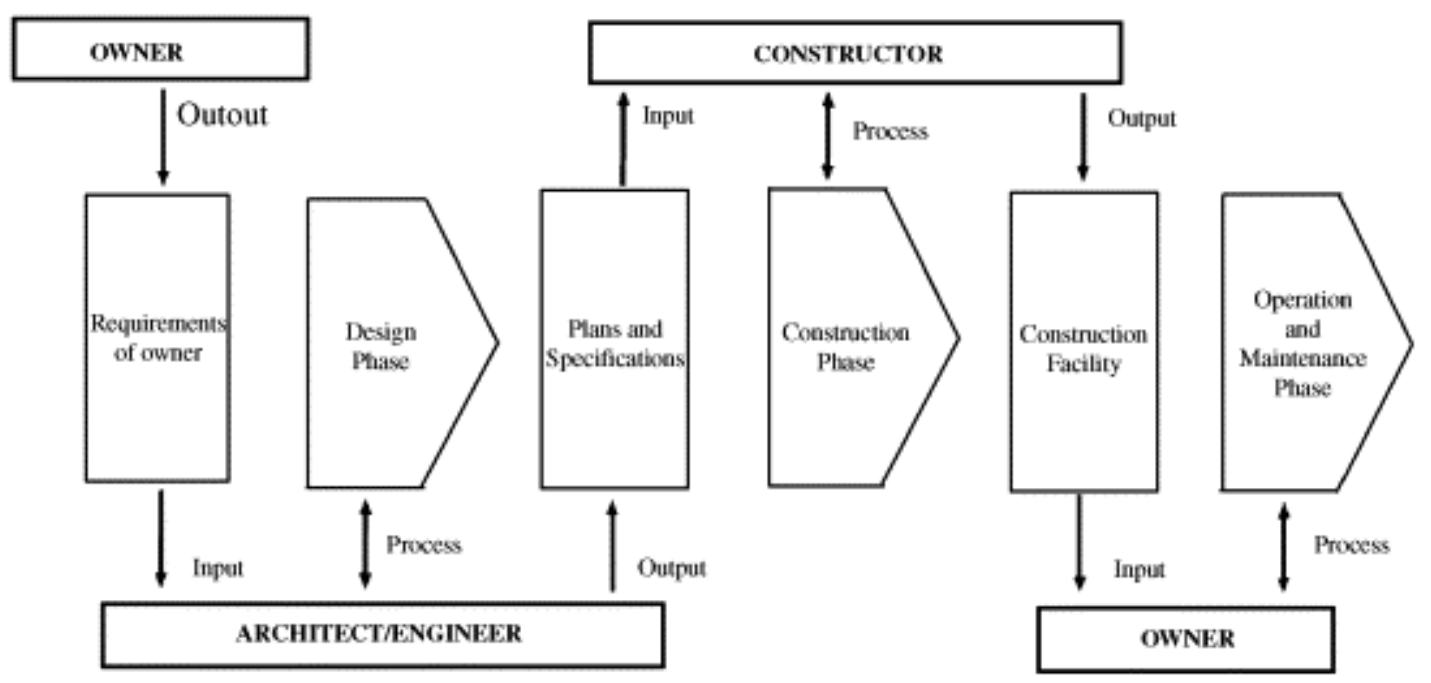

Fig. 1. Total quality flowchart for the construction project lifecycle illustrating TQM customer relationships. Arditi and Gunaydin. [16].

In the light of the above it is clearly apparent that to achieve quality in a constructed facility without adequate quality management during the design phase will present enormous challenges. The exact extent to which poor design quality is a contributing cause of construction project failure in South Africa is unknown and warrants further investigation, although reason and precedent would lead one to speculate that it may be significant.

Because of the subjective nature of many aesthetic concepts some architects shy away from the idea of applying quality management theory to architecture, claiming that in the long run it is merely a business management tool and cannot be used to improve the aesthetic of the built product. This argument fails upon closer examination however, as there are many perfectly objective criteria with which designs need to be evaluated long before one arrives at any talk of aesthetics. Le Corbusier [17] for example defines the 
purpose of architecture as that of creating emotions, as opposed to that of engineering, which is to create structures. However, he also mentions that the building must succeed at the practical level long before this point is reached, or the outcome is ruined. If these objective aspects can be executed successfully it can therefore be argued that the resulting work has a far better chance of ever attaining the poetic standard that is expressed by the first view.

All of these objective criteria can be defined and evaluated around the notion of customer satisfaction as the driver thereof. The concept of quality that relates it to customer satisfaction is more subtle than may at first be perceived, and this subtlety resides entirely in the manner in which the customer is defined. The ISO definition thereof as an organisation or person that receives a product [12] is quite intentionally generic in this regard and could be liberally interpreted within the context of architecture to include a whole host of stakeholders besides the paying client, such as end users, the public and the environment. Such an interpretation is encouraged by Juran [9], who defined these as external customers and interested parties. A design scope/brief that includes these parties (no matter how they are defined) therefore goes a long way to including most of what good buildings aim to achieve, and should silence most arguments against the use of QM in architectural design. On the contrary, it is apparent that the scope for application of QM in architecture is vast, and that it extends well into the design realm.

Because QM is essentially a process-based concept [12] it is important that the business processes to which it is to be applied are well understood. Architectural firms are essentially design and management service providers to the building/ construction industry. Typically the processes at work in such organisations are broadly classified as project-related or practice-related. The practice-related processes of the architectural organisation are typical in that they include, to a greater or lesser degree, the customary functions of financial, marketing, purchasing, human resource and public relations management [18], together with associated administrative processes. 
Production in the architectural service provision context involves the delivery of design, management and procurement services, with associated documentation, for use before and during construction, and is therefore project-related. Project-related processes are commonly defined and outlined in procedural plans of work that are an attempt to standardise work processes around a typical project format and provide a framework from which progress can be measured and controlled. Such plans of work, however, relate to project lifecycles only and therefore do not include internal administrative and management processes, many of which do significantly impact on the quality aspects of project deliverables. For this reason Jefferies [19] and Lipton [20] and [21] structure quality management processes into the following three broad sections so as to take cognisance thereof:

- the quality manual: all the processes that relate to the establishment of the quality system, its management and documentation,

- practice management: practice management and administrative processes that impact on the quality of project deliverables and therefore also on customer satisfaction, - design management and project control: essentially project-related processes as represented in the plan of work.

It is important to bear in mind that practice-related processes that do not directly impact on the quality of project deliverables and customer satisfaction (non quality-critical processes) are not considered within the typical framework of quality management processes [19], although within the context of the TQM approach this would naturally not be the case.

\section{Survey structure and distribution}

The questionnaire that was circulated to South African architects was broadly structured into four sections. The first was aimed at providing a profile of the respondent organisations in terms of size, location, turnover and number of architects employed while the second section tested the management of the organisation against the following eight management principles as set out in the ISO 9001 standard [22]: 
- Customer focus.

- Effective leadership.

- Involvement of people.

- Process approach.

- System approach to management.

- Continual improvement.

- Factual approach to decision-making.

- Mutually beneficial supplier relations.

These principles are well established in the literature and are widely accepted as essential to effective quality management. Testing the respondents for ISO certification concluded the second section.

The third section was to be completed only by those organisations not ISO 9000 certified and examined the respondent's quality management systems in terms of status, documentation and record-keeping, management and planning, resource management as well as design and production management. This section was also modelled around the requirements for quality management systems as set out in the ISO 9001 standard. The fourth section concluded by examining the respondent's perceptions of quality among architects in South Africa and the desirability and relevance of ISO 9000 certification.

The final draft of the questionnaire was distributed twice via email to 1400 individual registered architects throughout South Africa by the SACAP using their bulk email distribution mailing list (at present it is not possible to distribute bulk email to practices). All of the email addresses in this mailing list were confirmed to be active at the time of distribution.

Ninety one responses were obtained, representing a 6.5\% return on individuals. Of the 91 responses obtained 63 were returned via email and 28 by facsimile. All of the respondents were instructed to submit only one response per practice and the data were 
controlled in this regard prior to capture. Currently there are 1952 registered architectural practices in the country, not all of which are necessarily active [23].

According to the data obtained regarding the number of registered architects employed with the respondents, the average number of registered architects per practice is calculated to be approximately 2.8. The survey can therefore be considered to effectively have been distributed to approximately 504 practices of which 91 responded, thereby improving the response rate to approximately $18 \%$, if one accepts the above assumptions.

\section{Findings}

\subsection{Section 1: respondent profile}

The majority (70\%) of the respondent practices are located in Gauteng (40\%) and the Western Cape (30\%) and are mostly organised either as close corporations (33.3\%) or private companies (31\%). Most of them are small businesses employing a total of between 1 and 5 staff members (57.3\%), with 1 (47.7\%) or 2 (21.1\%) registered architects as in Table 1 and Table 2 below. The average number of architects per firm is approximately 2.8. 54.4\% of the respondent practices have an approximate annual turnover of below R 2 million with $40.8 \%$ of this group tuning over less than $\mathrm{R}$ 500 000/annum.

Table 1.

Respondent profile—number of architects employed

\begin{tabular}{|l|l|l|l|l|}
\hline $\begin{array}{l}\text { No. of } \\
\text { architects }\end{array}$ & Frequency & Percent & $\begin{array}{l}\text { Cumulative } \\
\text { frequency }\end{array}$ & $\begin{array}{l}\text { Cumulative } \\
\text { percent }\end{array}$ \\
\hline 1 & 43 & 47.78 & 43 & 47.78 \\
\hline 2 & 19 & 21.11 & 62 & 68.98 \\
\hline $3-5$ & 16 & 17.78 & 78 & 86.67 \\
\hline $6-10$ & 9 & 10.00 & 87 & 96.67 \\
\hline 11 or more & 3 & 3.33 & 90 & 100.00 \\
\hline
\end{tabular}


Table 2.

Respondent profile-total staff employed

\begin{tabular}{|l|l|l|l|l|}
\hline Total staff & Frequency & Percent & Cumulative frequency & Cumulative percent \\
\hline $1-5$ & 51 & 57.30 & 51 & 57.30 \\
\hline $6-10$ & 16 & 17.98 & 67 & 75.28 \\
\hline $11-25$ & 13 & 14.61 & 80 & 89.89 \\
\hline $26-50$ & 7 & 7.87 & 87 & 97.75 \\
\hline 51 or more & 2 & 2.25 & 89 & 100.00 \\
\hline
\end{tabular}

\subsection{Section 2: management principles}

In terms of the application of management principles all of the respondent practices perceive themselves to be strongly customer focused, and the overwhelming majority (97.7\%) consider their leadership to be effective in providing unity of purpose and direction within their organisation. 75\% of them deliberately manage their practices with a process-based system where decision-making is guided in $70 \%$ of the instances by factual data especially gathered for such purposes. The majority of the respondents (64.4\%) claim to formally implement processes that ensure the continual improvement of quality and $88.9 \%$ strive to achieve long term, mutually beneficial relationships with suppliers of materials and services.

Out of the 85 responses to the question of ISO 9000 certification only two confirmed that they were certified, representing $2.3 \%$ of that population. These two cases are therefore special cases that will be examined in greater detail later.

\subsection{Section 3: quality management systems and procedures}

Most of the non-ISO 9000 certified respondent practices (74.6\%) are managed without the discipline of a QMS. Where some form of quality management is being applied, it is done so in the overwhelming majority of cases in an "informal” manner. Most of the 
respondents claim to have informally identified quality critical processes and to have adopted a process-based management approach, although the operation and control thereof is once again largely informal.

Only $10.4 \%$ of the respondent practices posses a documented quality policy or documented quality objectives (16.2\%), and only $29.4 \%$ use documented work procedures and/or job instructions within the office. The principle whereby records are produced for third party evaluation is actually applied in only $10.4 \%$ of cases. Customer feedback is obtained occasionally but less often than not among the respondent practices, although the formal extraction of a brief is a principal well entrenched among the majority (59.5\% do it either always or regularly) of the respondents. Once again, most respondents claimed that service quality and the responsibilities and authority of staff in relation to it are clearly defined and communicated in their practices, but this is done informally. Routine management reviews and controls are also mostly executed informally (69.7\% of cases) or not at all (18.6\% of cases). Despite the above, most (83.3\%) of the practices are persuaded that their approach to quality is both adequate and appropriate to the type and complexity of the service they provide.

The manner in which resources are managed by the respondents is encouraging as it would appear that most of the principles required by the standard are well entrenched. Project related costs are monitored and recorded by the majority (55.8\%) of practices to assist and inform decision-making, and human resources are regularly appraised and trained in $64.6 \%$ of cases. Most practices felt that their human resources are possessed of an appropriate level of education, training, skill and competence, and that their equipment, infrastructure and working environments were suitable.

Similarly, the principles of design and production as given in the standard appear to be well entrenched. Customer needs and statutory requirements are always or regularly comprehensively evaluated and incorporated into the production and service provision of each project in $93.2 \%$ and $95.5 \%$ of the cases, respectively. $90.7 \%$ of the respondent practices possess clearly defined design criteria that are well understood and 
communicated within the organization, and $94.2 \%$ either always or regularly carry out design reviews to validate and verify their designs to ensure compliance with the above customer needs, statutory requirements and design criteria. Feedback from completed projects in terms of post occupancy surveys and the collection and collation of data for the purpose of continual improvement is carried out sporadically, with $44.3 \%$ of respondents claiming to do so regularly or always, and 55.6\% occasionally, seldom or never.

\subsection{Section 4: perceptions}

The responses regarding the desirability and benefit of ISO certification are summarised in the figures below. Because only two of the 91 respondents are ISO 9000 certified, their responses are not included here as this small sample size may distort the results and it would suffice to say that both the respondents were well disposed towards the advantages of such registration (Fig. 2, Fig. 3, Fig. 4, Fig. 5, Fig. 6 and Fig. 7).

THERE IS A NEED FOR IMPROVEDQM IN SA ARCHITECTURAL PRACTICES

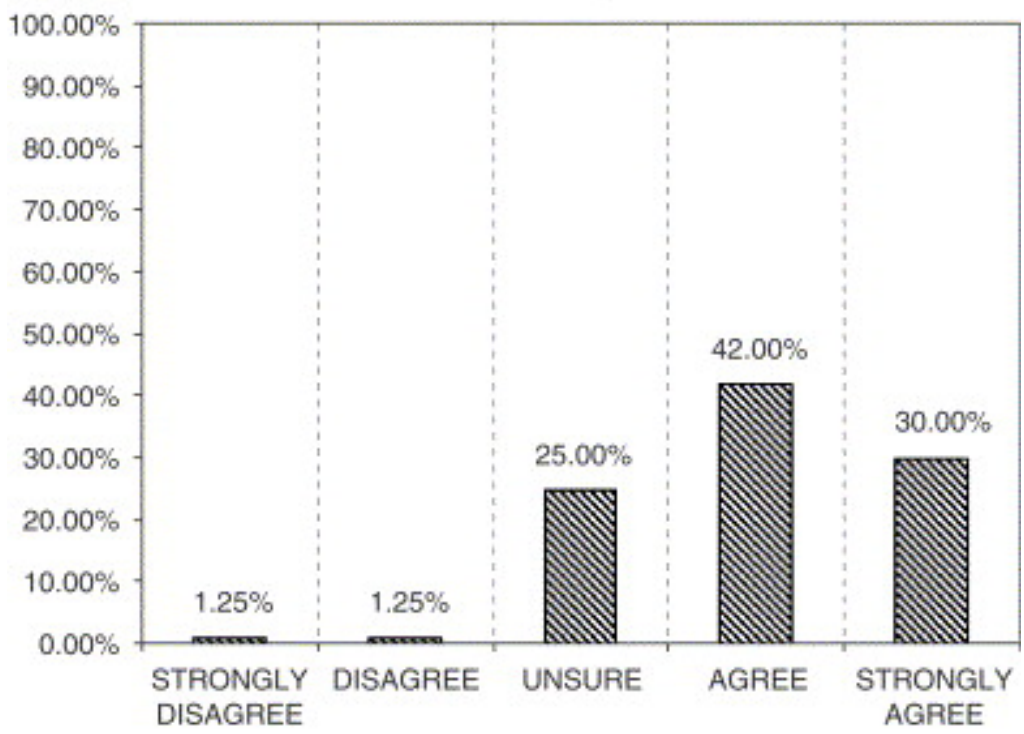

\$ NOT ISO 9000 REGISTERED

Fig. 2. The perceived need for improved QM among architects in SA. 


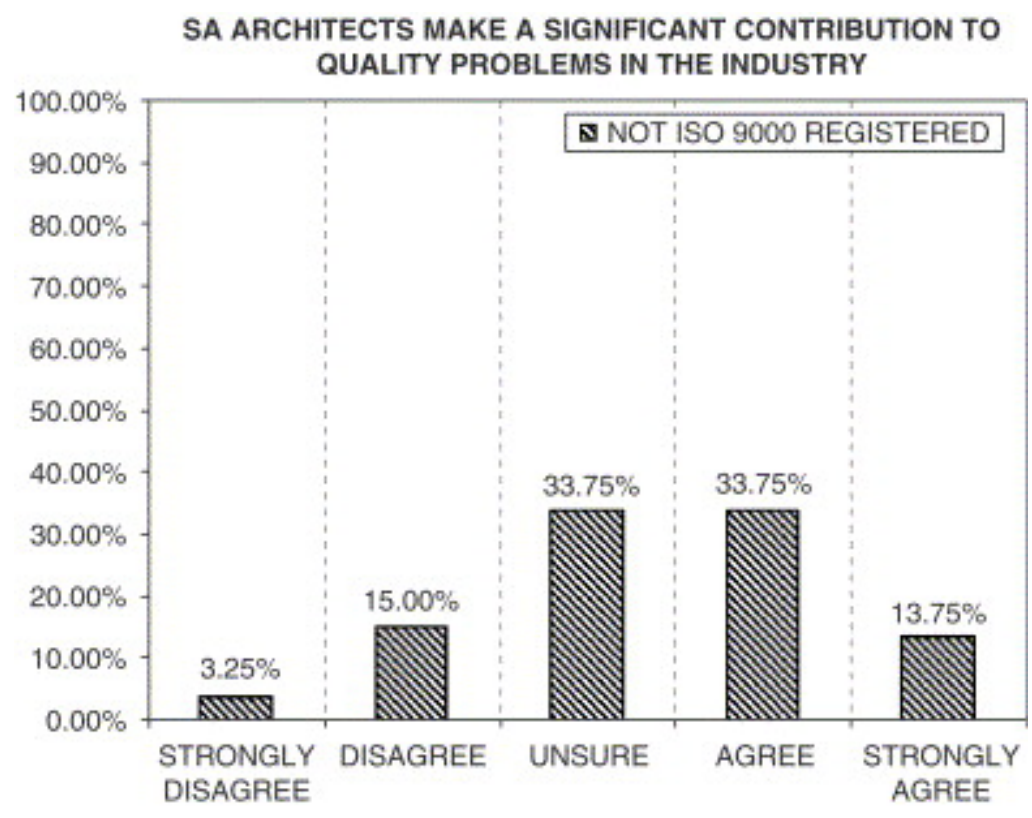

Fig. 3. The perceived culpability of SA architects with regard to quality problems in the local building industry.

MANDATORY ISO 9000 CERTIFICATION WOULD BENEFIT SA ARCHITECTURAL PRACTICES

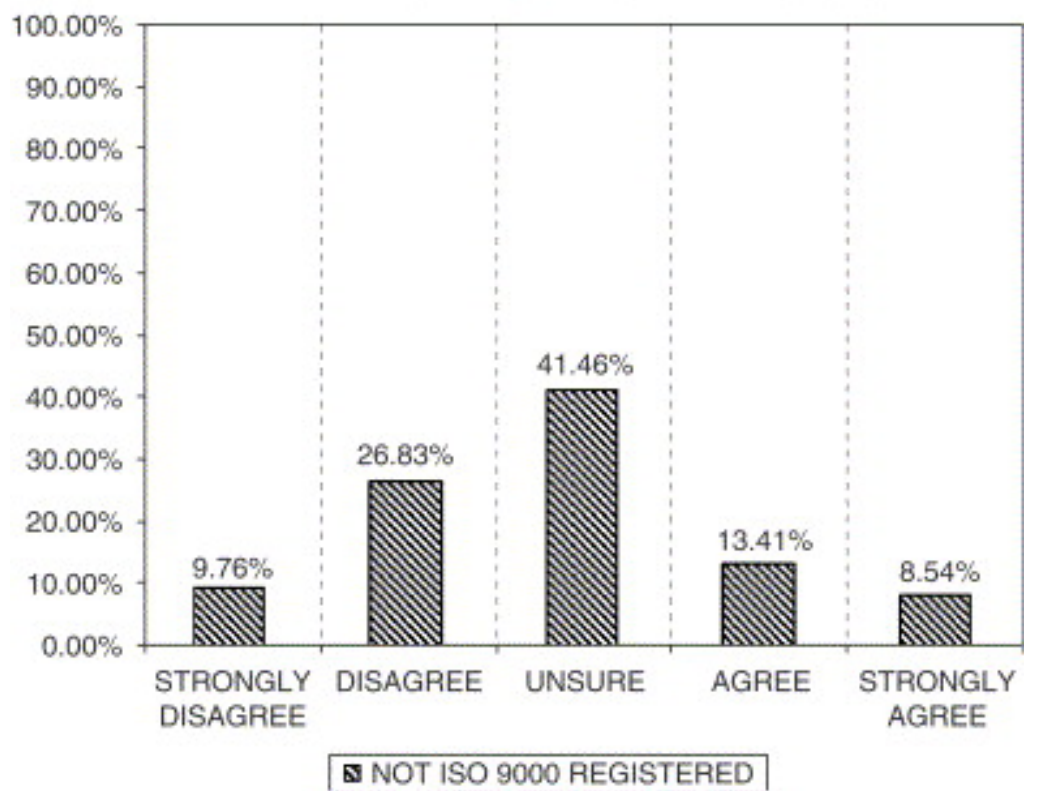

Fig. 4. The perception regarding the benefit of mandatory ISO 9000 certification. 


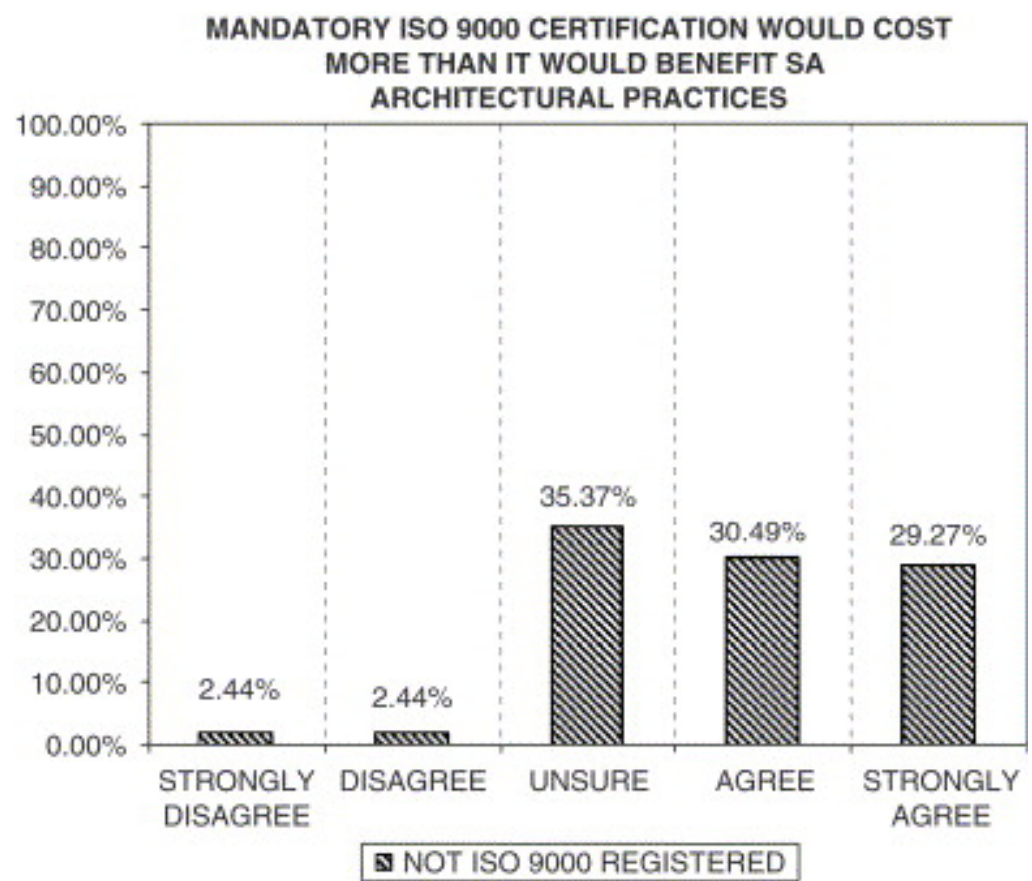

Fig. 5. The perception regarding the cost benefit of mandatory ISO 9000 certification.

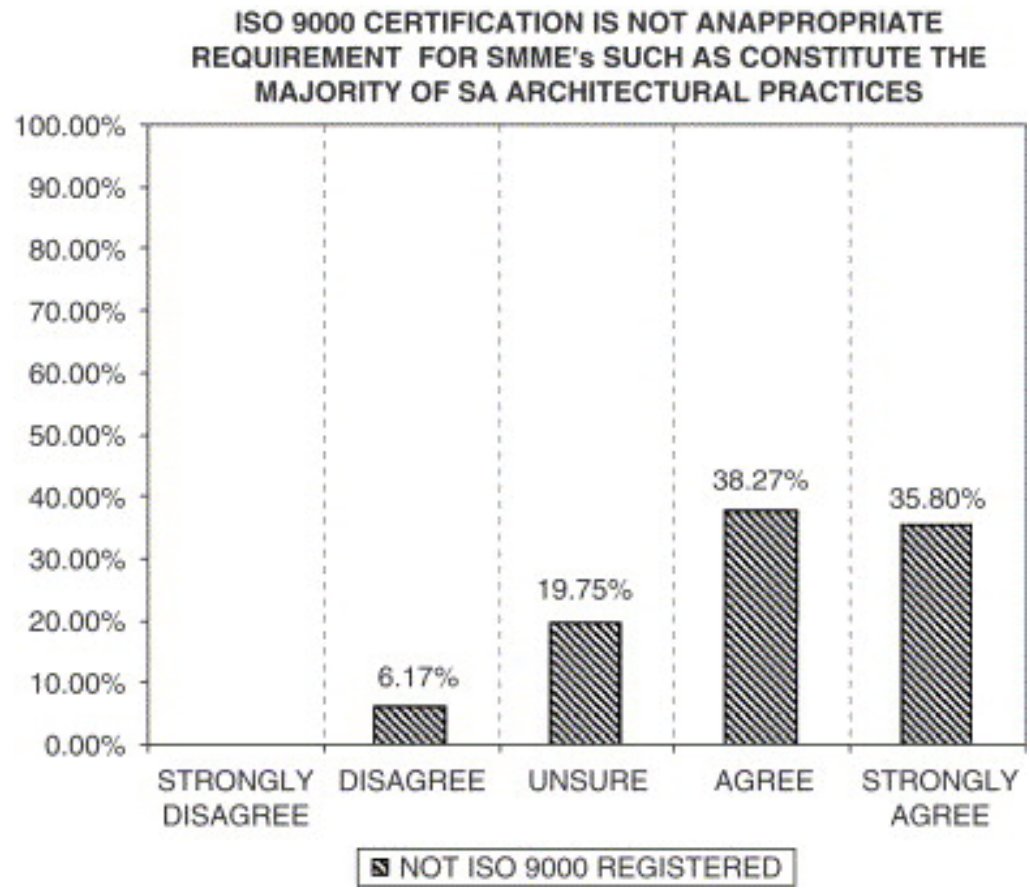

Fig. 6. The perception regarding the appropriateness of ISO 9000 certification to small business. 


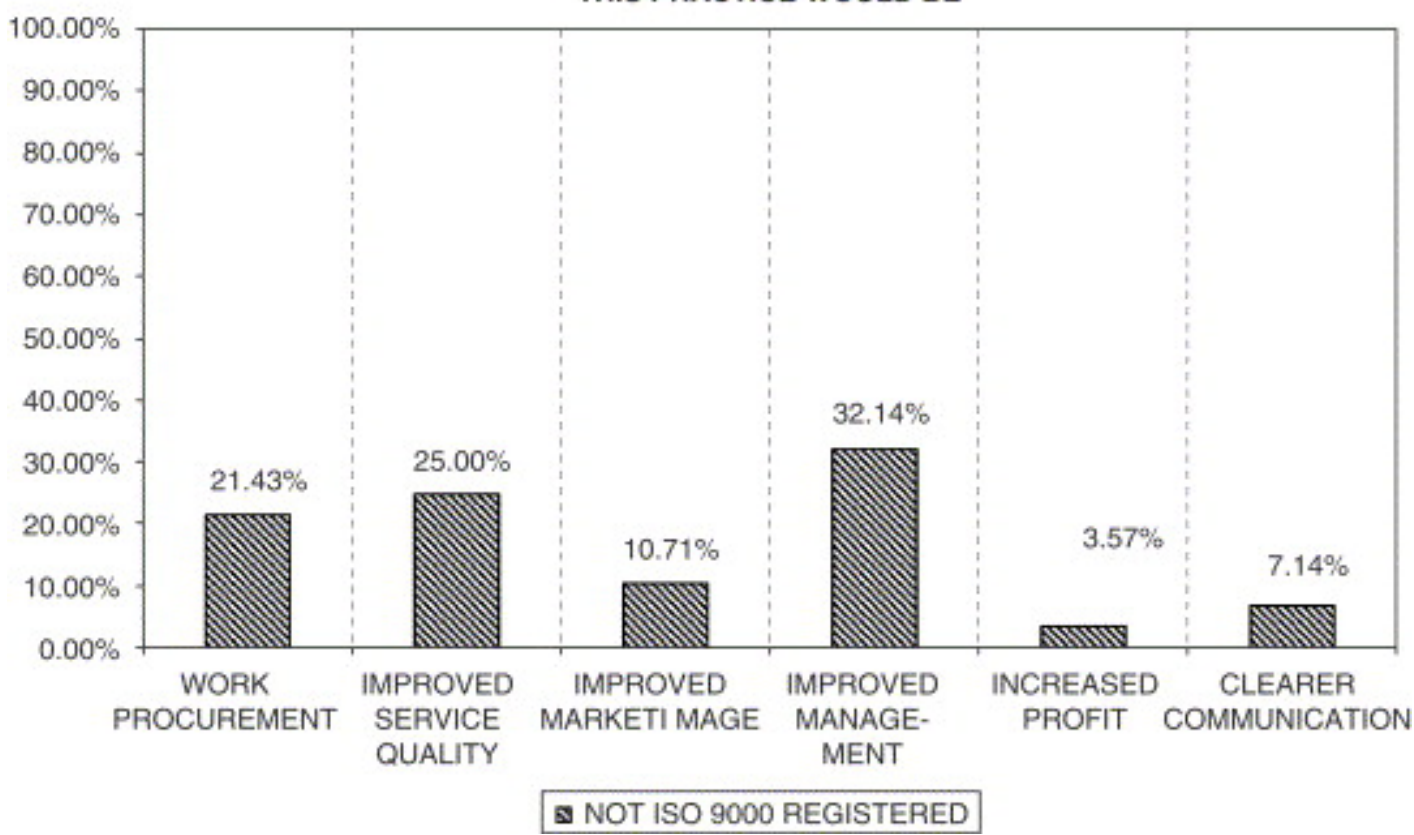

Fig. 7. The perceived primary advantage of ISO 9000 certification.

Although the response rate of $18 \%$ was disappointing, it can be deemed acceptable for this type of research. The fact that the population of architectural practices is fairly homogenous, particularly in terms of size and therefore also management requirements, lends one some license to assume that the study is more representative than what the percentage return suggests. For the sake of avoiding criticism in this regard however, the conclusions below are limited to the respondent practices.

The following conclusions can be drawn from the study:

- The majority of respondent practices are intrinsically possessed of many of the management principles required for the proper management of quality.

- Despite this these practices do not manage quality in accordance with quality management theory as it is presented in the literature.

- The manner in which quality is managed by these organisations is unstructured and unsystematic, with a strong aversion being demonstrated to documentation and record keeping. 
- An exception to the above is evident with brief extraction and conformance to statutory requirements, which is conducted with a much greater degree of formality.

- There is a widespread consensus among the respondents that there is a need for improved quality management among South African architectural practices, and that architects do significantly contribute to quality problems in the industry.

- Very few of the respondents view enforced ISO 9000 certification as a means of addressing these problems in a positive light. The majority believe that professional registration is sufficient to ensure service quality. This is contradicted by those respondents that are already ISO 9000 registered, and who are generally well disposed towards the advantages of such registration, and believe professional registration to be inadequate to ensure service quality.

- There appears to be a poor understanding and knowledge of quality management theory and techniques among the respondents.

This immediately raises the question as to whether this is problematic and what, if anything, should be done to correct it if it is. As quality problems pervade the industry at present and architects as designers occupy a position that strongly influences the quality of downstream activities it would be difficult to motivate an opinion that denies the extent or reality of the problem.

\section{Conclusions and recommendations}

Because of the influential position that designers occupy as regards downstream quality they are a crucial link in the project lifecycle chain and any campaign to address quality within the industry will need, as a matter of course, to include them as such. At present the drive to reform the industry in South Africa is still in its infancy and is not as yet characterised by a strong, visible leadership commitment to quality by all the associated participants. Given the losses that poor quality generates, and international trends toward improving the situation within the industry, this state of affairs is unlikely to last long before powerful clients begin to impose their preferences on how to address it. A preemptive action to address quality from within the industry would therefore be a prudent exercise that could help to mitigate the effect of yet more legislative restrictions and 
controls. This raises the question of how such inclusion is to be implemented and in what form, and whether enforced ISO 9000 certification is a strategy worth considering. It is important that the approach should not be that of imposing quality on a reluctant industry but rather that of creating and nurturing a pervasive culture of quality. As with any such effort visible leadership commitment is essential. As the governing body that protects the interests of the public with regard to the profession, the South African Council for the Architectural Profession (SACAP) should lead the undertaking and the South African Institute for Architects (SAIA) and its regional bodies should assist their membership with the implementation thereof. This should be done visibly and in cooperation with quality bodies such as the South African Quality Institute, and in consultation with quality experts that can guide the process. An important aspect that must be addressed is education and this could be done through both the CPD programme as well as through educational institutions.

Insofar as enforced ISO 9000 certification is concerned the architectural fraternity would be well advised in this regard to bear the results of McAdam and Canning's study [8] in mind, and the conclusion that unless motivated by a real desire to improve quality and service excellence among practitioners, mandatory registration/certification can produce disappointing results. Also, the enthusiasm for certification that prevailed in Europe during the 1990s but produced little in terms of real quality improvement should be taken cognisance of. The objective of any quality programme must be to continually nurture a culture of quality, creating in the process an environment in which quality will flourish, and not merely to seek the assurance that something is being done. A strong argument exists therefore in support of the position that ISO 9000 certification should be a voluntary undertaking that constitutes a waypoint or milestone in an organisation's journey toward improved quality, and as such will only be undertaken if and when it makes good business sense to do so. It should ensue rather than be pursued. The positive response in this study from the two ISO certified practices with regard to the benefits thereof is probably due in part to the fact that their registration has to date been voluntary, and it is this attitude that should be engendered by whatever action is taken. That is not to say however, that incentives should not be used to encourage ISO 9000 certification, but 
merely that if used they should not be coercive, especially in view of the negative opinion that the majority of the respondents still possess in this regard. Such incentives could take the form of rebates on professional indemnity insurance due to the decreased liability risk, CPD credits, improved ratings with client bodies etc. not to mention the advantage to the organisation of delighted customers, reduced costs and increased profits as a result of less repeat work. Clients should also be encouraged to require evidence of a working quality system from their professionals at the time of appointing them.

The literature strongly suggests that the most challenging aspect of implementing a quality drive lies in changing the attitudes of the participants. Sir John Egan's task force, required to advise the Deputy Prime Minister from the clients' perspective on the opportunities to improve the efficiency and quality of delivery of UK construction, identified five key drivers for change in the construction industry [5]: committed leadership; a focus on the customer; integrated processes and teams; a quality driven agenda; and, commitment to people. Four of these five drivers centre on people and the complexities of managing them, and the other on a quality culture. The implementation of quality management systems should not be seen as something additional to what architects already do but rather as a form of process control that needs to be applied to existing processes so that they reinforce the quality principles already existent in many practices.

\section{References}

[1] B. Perkins, Design quality is central management issue: part II, Architectural Record (1984), pp. 33-35.

[2] South African Association of Consulting Engineers. Advisory note: implementing and maintaining a quality management system. http://www.saace.co.za/QMS/2.phtml (Access: November, 2005).

[3] J. Haywood-Farmer and J. Nollet, Professional service firms and total quality management: a good fit?, International Journal of Service Industry Management 5 (4) (1994), pp. 5-13. 
[4] Latham M. Constructing the team: final report of the government/industry review of procurement and contractual arrangements in the UK Construction Industry. The Stationery Office, London; 1994.

[5] DTLR (Department for Transport, Local Government and the Regions). Rethinking construction. Office of the Deputy Prime Minister, London; 1998.

[6] P.D. Rwelamila, Quality management in the SADC construction industries, International Journal of Quality and Reliability Management 12 (8) (1995), pp. 23-31. [7] W. Coxe, Managing architectural and engineering practice, Wiley, New York, NY (1980).

[8] R. Mcadam and N. Canning, ISO in the service sector: perceptions of small professional firms, Managing Service Quality 11 (2) (2001), pp. 80-92.

[9] J.M. Juran et al., Juran's quality handbook (5th ed), McGraw-Hill (1999).

[10] J.D. Van der Bij and H. Broekhuis, The design of quality systems: a contingency approach, International Journal of Production Economics 55 (1998), pp. 308-319.

[11] A. Ghobadia and D. Gallear, Total quality management in SMEs, Omega, International Journal of Management Science 24 (1) (1996), pp. 83-106.

[12] SANS 2000. 2nd ed. Quality management systems_-fundamentals and vocabulary. Pretoria: South African Bureau of Standards; 2000.

[13] T. Cornick, Quality management for building design, Butterworth-Heneman Ltd, Guildford (1991).

[14] B. Fynes and S. de Burca, The effects of design quality on quality performance, International Journal of Production Economics 96 (2005), pp. 1-14.

[15] S.J. Ahire and P. Dreyfus, The impact of design management and process management on quality: an empirical investigation, Journal of Operations Management 18 (2000), pp. 549-575.

[16] D. Arditi and H. Gunaydin, Total quality management in the construction process, International Journal of Project Management 15 (4) (1997), pp. 235-243.

[17] Le Corbusier. Vers une Architecture. Paris: G. Crès; 1923.

[18] G.J. Cronje, G.S. du Toit and M.D.C. Motlatala, Introduction to business management (5th ed), Oxford University Press, Oxford (2000). 
[19] T. Jefferies, A model for a quality management system, RIBA Enterprises, London (1999).

[20] S. Lipton, Architect's handbook of practice management (7th ed), RIBA Enterprises, London (2001).

[21] S. Lipton, Architect's job book (7th ed), RIBA Enterprises, London (2002).

[22] SANS 9001. Quality management systems—requirements, 3rd ed. Pretoria. South African Bureau of Standards; 2000.

[23] South African Council for The Architectural Profession (SACAP). Informal telephonic interviews and email correspondence; 2005.

Corresponding author. 